\title{
Premises and Convergent Factors of Regional Development
}

\author{
Margarita Alekseevna Afonasova \\ Tomsk State University of Management Systems and Radio Electronics \\ Email: afonasova@yandex.ru
}

\section{Doi:10.5901/mjss.2015.v6n3s4p191}

\begin{abstract}
In article are considered approaches to the overcoming problem resolution of regional inequality, the accruing territorial differentiation and disintegration, which becomes the primary factor, which is slowing down social and economic development of the country. The main factors promoting regional convergence development in the instable world and domestic economy conditions, adverse external environment, economic sanctions of the western countries are investigated. The relevance of forming of the convergent strategy development of regions directed at overcoming of territorial disintegration and a regional inequality is proved. The essence and a role of convergence of social and economic systems are revealed; hypotheses of convergence and divergence are investigated. The conclusion that strategy of convergent development can play consolidating and stabilizing factor role, means of ensuring of social and economic stability, increase of competitiveness and economic safety in regions in medium-term and long-term perspectives is drawn. Based on the analysis of essence, the principle, types and the main mechanisms of convergence are revealed and characterized; a set of the managerial measures promoting the convergent development of the Russian regions is defined. It is proved that the main premises, convergence regions engines in modern conditions are transport and construction, which promote most mobility of major factors of production, attraction of qualitative labor power, increase of investment appeal of the region.
\end{abstract}

Keywords: convergence, divergence, regions, development, management.

\section{Introduction}

The most significant problems of any state are the maintenance of the territorial integrity of the country, prevention of the social conflicts, any crises, providing a worthy level of population living. Today in the Russian Federation is observed the highest level of regional differentiation of the main socio-economic indexes. Moreover, the number of the problem and lagging behind regions tends to growth that is explained by the action of a number of both objective, and subjective factors. The need for the solution of the specified tasks causes relevance of research of problems of territorial disintegration, a regional inequality and regional convergent concept development. Development of the region represents a multiple changes of its states, on condition of preserving of positive tendencies of growth. Economic regional development belongs to economic part of this multiple change, and social - to social part. Prof. I. S. Karabulatova, analyzing a mega concept "region", gives over hundred of its definitions which reflect this or that accent of researchers depending on a professional and target orientation (Karabulatova 2001: 48). Means and the level of social or economic development of the region have to reflect this plurality of changes, results of system development. The concept "convergence" was entered in 1873 by the English physicist J. K. Maxwell, working on the creation of an electromagnetic theory field. In the economic theory, the concept of convergence was formulated within the neoclassical model of economic growth of R. Solow (Solow, 1956).

Convergence means rapprochement towards merge, stable equilibrium. In a literal sense, convergence consists in the independent development of identical signs in different systems because of adaptation to similar conditions or circumstances (Azriliyan, 2005). The hypothesis of convergence represents the statement that how economic systems differed among themselves, in the course of evolution they discard inefficient institutional forms, selecting and keeping the effective. Therefore eventually all of them after such gradual (evolutionary) selection will be rather identical, i.e. are similar to each other.

Arguments of supporters of this hypothesis consist that the latest technologies, means of communications and transport extend everywhere, creating a unified technical and technology basis for the development of the different countries and societies. A certain general technical basis creates a basis for deleting of country distinctions. Distribution of technologies of planning and similar planned the technician in the countries of the world with different political systems became one more argument for the benefit of convergence. Now the term "convergence" is used even more often at the 
description of integration processes. The general tendencies and factors of scientific and technical and social and economic progress are the cornerstone of world integration development. They cause rapprochement, i.e. convergence, economies is more increasing than number of the countries when preserving their national features.

Distinguish conditional and absolute convergence. Conditional convergence assumes the availability of positive dependence between the growth rate of economy and distinction of the current and equilibrium income levels. It differs from the absolute convergence assuming that the poor countries (regions) develop higher rates than rich, catching up with them.

Rather often, the hypothesis of convergence is tested on the example of regions as there are considerable discrepancies between regions on a level of development of technologies, productions, economic institutes, etc. The therefore probability of availability of absolute convergence between regions rather high. It is necessary to consider that the policy of the central government is directed, as a rule, on smoothing of interregional distinctions and in support of the development of rather poor regions.

The process opposite to convergence is called as divergence. Divergence is a discrepancy of signs of social and economic educations during evolution. The fight for existence, survival, supports divergence. The principle of divergence explains the process of formation of larger groups and emergence of gaps between them.

Diagnostics of regional development is carried out by the interested authorities, public and other organizations, subjects of managing, separate research collectives and physical persons. The central authorities proceed, first of all, from interests of the country in general, and also pursue industry and other aims. Regional authorities consider possible options for providing optimum living conditions for the population of the region. Separate research collectives and physical persons execute the corresponding orders of authorities and subjects of managing.

The generalized these diagnostics form information base for acceptance of management decisions on achievement of steady functioning of regions, elimination of unjustified distinctions in a level of living of the population of different territories. On their basis plans, forecasts of economic and social development of regions are developed. Diagnostic information is necessary also for banks, investment companies, the exchanges at strategy development of capital allocation and forming of the regional markets.

\section{Methods and Materials}

Different types of convergence cause the availability of several methodologies of their analysis. Given the complexity of this problem, its satisfactory solution can be achieved only through the involvement of a wide arsenal of mathematical economics.

The region from positions of socio-economic analysis of its level development, represents complicated object, it is impossible to estimate which condition on any one indicator (Karabulatova, 2001; Karabulatova \& Polivara, 2013; Ryazantsev \& Bozhenko, 2014 \& Ryazantsev et al, 2014). It is caused, that consolidation of such regional subsystems as the industry, transport, the agricultural industry, services, education, health care, legal assistance, etc. in some whole the region, - is very conditional. The system as an object of research represents some hierarchically arranged set of the elements and systems integrated with the achievement of some purpose (or sets of the interconnected purposes). In the region, if to consider it from these positions as a system, such unification is not present. Many of his works subsystem with the objectives inconsistent with the purposes of development of the region or only indirectly related. For example, the large industrial enterprise working in the region, but belonging to owners from other region or the country functions for maximizing the income of the owner.

Considered that the easiest way it is possible to analyze availability of convergence at rates of economic development from the point of view of reduction of an inequality in the level of per capita GDP (VRP) among group of regions (i.e. the concept is considered $\sigma$ - convergences). For verification of the theory $\beta$ - convergences the regression analysis (cross-section) of selection of regions in which dependence of the gain of real VRP that is saved up for some time frame on the VRP initial level per capita is estimated is usually used. From the methodological point of view, check of a hypothesis of convergence based on time series analysis of indicators of the income on regions and researches of their dynamic characteristics is more difficult. However absence enough long ranks of data on regions of the Russian Federation (and especially on municipalities) complicates the use of a method of time series for a check of a hypothesis of convergence.

According to data of Russian Federal State Statistics Service of VRP per capita adjusted for interregional distinctions of the prices of Khanty-Mansi Autonomous Area leading on this indicator more than by 41 times, exceeds VRP per capita of the Republic of Ingushetia. Stronger differentiation is observed on indicators of investment activity. For 
example, on an indicator of the amount of investments per capita. The difference on this indicator of the leading and lagging behind regions of the Russian Federation makes 190 times. So strong level of interregional distinctions generates an aggravation of social problems in unsuccessful regions, complicates interregional economic cooperation, and limits growth rates of the national economy. The investment appeal of the region is defined by NRA rating as a set of the factors influencing expediency, efficiency and level of risks of the investments in the territory of this region. These factors are an active background for all investment projects realized in the area of the region influence risk and profitability of project data.

The investment appeal of the region consists of several factors, each of which can be estimated by means of proxy selection and variables for it. In a rating seven factors of regional investment appeal are considered:

1) Security of the region for natural resources and quality of environment in the region: availability main types of natural resources in the region (including fuel and energy), the level of environmental pollution, possibility of drains and processing cleaning of production wastes.

2) Region manpower: main characteristics of a manpower of the region, including number of economically active population, level of employment and unemployment, the volume of the offer of skilled labor force, and also labor productivity.

3) Regional infrastructure: the level of development and availability of both "tough", and "soft" infrastructure. The concept of "tough" infrastructure joins transport, power, telecommunication, and housing infrastructure. The "soft" infrastructure includes some components from which from the point of view of investment appeal the financial infrastructure has the greatest value.

4) Domestic market of the region (potential of regional demand): domestic market level development of the region (including scales of sectors of retail trade and paid services), disposable income and purchasing power of the population of the region.

5) Potential production of regional economy: cumulative results and features of economic enterprises activities which are already working in the region (volume and dynamics of production, the size of assets, their quality and efficiency of their use).

6) Institutional environment and socio-political stability: expert evaluation of the effectiveness of regional legislation regulating the interaction between government and investors, expert assessment of the favorability of the regional tax law (the existence of tax benefits and opportunities to obtain them), the level of social and criminal tensions in the region.

7) Financial regional budget stability and enterprises of the region: a condition of public finances in the region (the amount of tax revenues, a budget balance, a regional national debt), and also an assessment of a financial position of the enterprises of the region (profitability (unprofitability) of firms, a state creditor and accounts receivable of the organizations, availability of investment resources) (Methodology of a rating, 2014).

There is a point of view according to which the policy directed at reduction of distinctions in levels of economic development of regions inevitably attracts reduction of growth rates of national economy and vice versa, GDP growth can be provided with only a price of deepening of an interregional inequality. Within the forming theory of feedback, it is proved that positive feedback always lead to the growth of interregional differentiation, despite the regulating actions of the Federal center. The resources spent for support of the lagging behind regions can only reduce the speed of increase of interregional distinctions, but it will occur due to the reduction of growth rates of the economy.

In this article, the opposite thesis according to which the positive feedback existing in national economy working for deepening of interregional distinctions can be compensated for the account of effective influences of state bodies is protected. For justification of this point of view, the concept of convergent development of the Russian regions and management model a regional economic system, combining elements of convergence and divergence is offered.

\section{Results}

The concept of convergent development offered by us allows to draw very important conclusions concerning opportunities for basic mechanisms of reproduction of a social and economic order, and also to correlate among themselves understanding of processes of the organization and self-organization in the context of ensuring stability of regional system.

First, possibilities of increase of efficiency of social and economic system, its stability are limited to the structure of an order within which the corresponding policy is performed. Secondly, it is revealed that when the system reached some optimum of effective functioning, all subsequent efforts will not lead to the further growth of efficiency. Therefore, an exit for the system is the substitution of the existing social and economic order with a new order. And so far there is no 
definite answer to a question: whether there will be a substitution of one order by another on the basis of free selforganization or it is necessary to manage this process, i.e. change of an order will be performed on the principles of the managed self-organization.

The analysis shows, that in the modern practice of the Russian reformism the explicit list towards attention to an organizational component to the detriment of self-organizational is observed, that generates a set of inadequate projects and reformatory decisions. For the organizational processes presence of the particular managing subject initiating processes of transformation on the basis of the rational judgment performing these processes by means of programs, regulations, organizational control is characteristic. The aspiration to formalization, a regulation is one of the main parties of such strategy.

For self-organizational processes, structural educations are characteristic of spontaneity. Specialists note the primacy of the self-organizational component in social and economic ordering processes. Organizational efforts can be successful and generate steady structures only at a considerable reinforcement from a self-organizational component (Bevzenko, 2003). Force and imperativeness of self-organizational processes are capable to suppress any organizational efforts. In our opinion, both specified process can be integrated and investigated within the uniform concept of convergent development of social and economic systems. In this case, it is possible to speak about possibility of a resonance of organizational and self-organizational processes, their coordination, therefore, the system can have regulation at the level of a choice of the attracting attractors, result of that will be changes of quality of its elements. An instrument for ensuring the unity of organizational and self-organizational processes in society within the offered concept is a public administration that purpose consists in providing conditions for a dynamic, sustainable development of society. For this purpose, it directs the efforts to the removal of obstacles in the course of free social and economic self-organization, on the support for steady functioning and development of economy and society.

Thus, the regulations on the unity of forms of public orderliness formulated by us - self-organization, the organization and means of their providing - public administration, are the central fragment of the convergent development concept. Public administration is considered in this context not only as a function of the organization and manifestation of self-organization, but also as an implementer of public orderliness in both forms.

Within the concept of convergence, the problem of development of the strategy of management of the innovation development (that is the extremely important for Russia) based on mechanisms of the managed self-organization can be efficiently solved. Such plan of management has to combine the hierarchical organization with normative regulation and control organically, on the one hand, and with the new functions directed by perception of the weak signals and changes stimulating positive tendencies of development and an innovation - with another. Creative self-organizational processes and public administration have to act in the space of regions as the continuous parties and factors of providing a convergent development trajectory.

The combination of self-organization and public policy in convergent social and economic system provides its functioning by means of mature market mechanisms, achievement of the maximum effect of the innovation and investing activities, and also rather equitable distribution of the income that opens a way to desirable harmonization of interests (from the point of view of decrease in a social conflicts) entrepreneurs - capital owners, and other citizens at all levels of management (nationwide, regional, local).

On the basis of identification of essence and contents of the concept of convergent development, processes of self-organization and management in a local economic system, and also factors and mechanisms of convergence the management model development of economy of the region combining elements of convergence and divergence was developed. In the model are mortgaged the development mechanisms of an economic system of the region based on the use of positive and negative feedback. Positive feedback lead to a swing of the system, to its transformation, accumulation of high-quality changes. Negative communications on the contrary, are directed at preserving the available structures and the relations, on ensuring the stability of the system. Therefore, any crises in the system are defined by the strong influence of positive feedback, consecutive strengthening of the effect of small influence (Dolyatovsky et al., 2001).

The model is implemented author's point of view, according to which non-linear positive feedbacks working to deepen inter-regional disparities will "disperse" the regional economy, increase its growth rate, and the consequences will be compensated by corrective action of the government. That is at the heart of this model is the idea of self-driven regional economic system.

Development of public-private partnership in subjects of the Russian Federation for 2013 is provided in figure 1. (A rating of regions 2014, p. 5). 


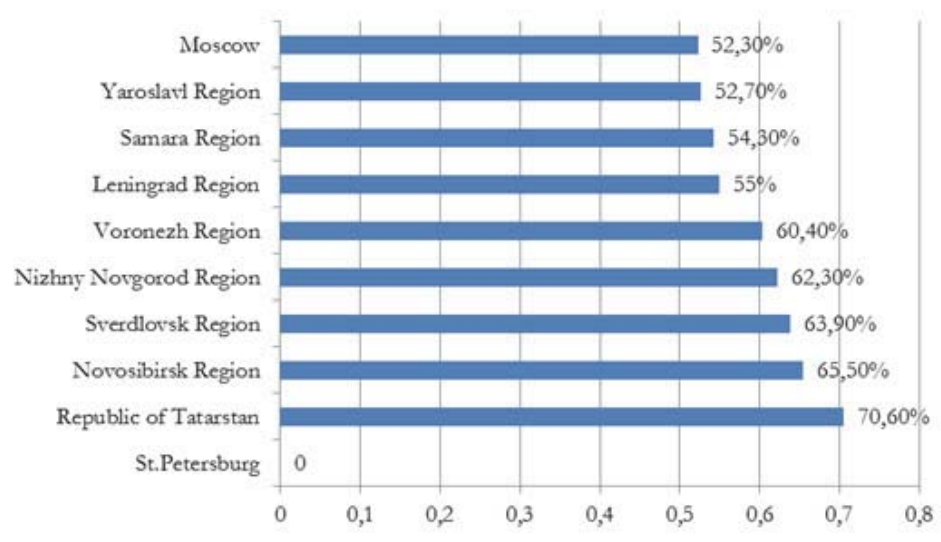

Figure 1. Development of public-private partnership in certain subjects of the Russian Federation for 2013

\section{Discussion}

The term "divergence" is used in economy for designation of the movement on the dispersing trajectories: increases in a gap between levels of development of the certain countries, strengthening is of distinctions between national models of economy, their separate structures and mechanisms. Besides, this term is also used for the designation of a deviation of the certain countries or regions from average macroeconomic values for any group of the countries or regions. Dozi (2005) and Item Druker (2012) considered separate aspects of the analyzed problem. All leading world concerns live with the middle of the 1940th years "on Druker". Druker believed that it was possible to create economic progress and social harmony (2012).

Regional divergence is considerably shown in the increasing role of capital megalopolises and regional capitals. In 2008 , the regional centers concentrated a third of the population and investments, more than $60 \%$ of trade, public catering and services (Nefedova, 2008). By the beginning of 2015, regional polarization even more amplified, and the problem of the space distribution of human capital became aggravated. The last population census revealed in the Russian Federation 34 thousand of "dying" villages with the population less than 10 people (24\% of all settlements). Besides, more than 13 thousand villages have no constantly living community at all (Population size, 2010). Annually from the Russian Federation card a large number of small settlements disappears. For example, for the last three years rate of reduction in a group of the small cities (to 5 thousand inhabitants) made ten cities in a year.

So, in Russia there is a group of backward regions which are for a number of reasons not ready to adapt to imperatives of scientific and technical progress, the innovation development, for changes in the regional and world markets. As a result the gap between them amplifies and leading regions, fix their backwardness, i.e. divergence takes place. On statistical data divergence between the absolute sizes of a per capita income in donor regions and in the depressive and underdeveloped Russian regions differing in the lowest indicators of resource security and infrastructure familiarity most of all goes deep.

Table 1. Approaches to determination of essence of development of the region

\begin{tabular}{cl}
\hline Author / Source & Determination \\
\hline Kovalenko E.G. & $\begin{array}{l}\text { Regional development is the mode of functioning of regional system which is oriented to the positive } \\
\text { dynamics of parameters of level and quality of life of the population provided with the steady, } \\
\text { balanced and multifactorial reproduction of social, economic, resource and ecological capacities of the } \\
\text { territory (Kovalenko, 2010: 64). }\end{array}$ \\
\hline Gavrilov A.I. & $\begin{array}{l}\text { Development of the region - multidimensional and multidimensional process that is usually considered } \\
\text { from the point of view of a set of different social and economic targets (Gavrilov, 2010, p. 67). }\end{array}$ \\
\hline Podprugin M. O. & $\begin{array}{l}\text { Development of the region is understood as any progressive change, first of all in the economic } \\
\text { sphere. This change can be quantitative, and then speak about economic growth. It can be qualitative, } \\
\text { and then tell o structural changes of the content of development. Along with economic characteristics } \\
\text { consider social parameters of development. Moreover, social characteristics are full indicators at an } \\
\text { assessment of the extent development of the region (Podprugin, 2012). }\end{array}$ \\
\hline
\end{tabular}


Thus, authors express the similar point of view. However, we consider that Kovalenko E.G. most fully defines contents of this term. So, development of the region is usually considered from the point of view of a set of different social and economic targets. Even if it is only about economic development, it is often considered together with social and includes: a) increase in production and income; b) changes in institutional, social and administrative structures of society; c) changes in public consciousness, in traditions and habits.

Such understanding of regional development essentially distinguishes it from processes of mechanical growth or structural complications. For example, it is impossible to refer to original regional development unilateral saturation of the territory industrial facilities (the practice of development of the Russian North, Western Siberia, virgin lands).

The Main objective of regional economic development is the improvement of the population life quality. The purposes of the region development are the increase in the income, improvement of education, a food and health care, poverty reduction, improvement of environment, equal opportunities, expansion of a personal liberty, enrichment of cultural life, etc.

The essence of sustainable development assuming the dynamic process of the consecutive positive changes providing a balance of economic, social and ecological aspects has to be the cornerstone of forming of approaches to the problem resolution of territorial educations.

It is especially actual today when there is a transfer of the center of gravity of economic reforms on the level of regions and strengthening of their role in the implementation of the economic policy of the state.

Stability of regional development defines capability to keep and develop value of necessary parameters of population life quality within a threshold of safety or above it at fluctuations of the external and internal influences (political, social and economic, technogenic, climatic and other character) threatening with falling of quality of life of the population.

The term "sustainable development" causes disputes in the Russian literature. Its English original (sustainable development) is exposed to criticism as the phrase, doubtful from the point of view of formal logic. Even in the usual speech the concept "development" bears with itself energy, speaks about changes whereas the concept "steady" bears in itself a sense of an invariance and safety. As for the transfer accepted in Russia, it does not convey adequately meaning of the initial English term meaning "the development which is not undermining own premises and conditions" or "development which can be supported vaguely long". In Russian is not present for it and an exact semantic equivalent, it can be translated as the "self-sustaining", "equilibrium", "continuous", "balanced", "acceptable" development (Svetunkov, Zagranovskaya \& Svetunkov, 2012, p. 29).

Long-term researches of regional inequality problems carried-out and analysis allowed to reveal the main mechanisms of convergence (figure 1) and to define set of the managerial measures promoting convergent development of regions: stimulation of the innovation activity and technology transfer, encouragement of production factor mobility, structural adjustment of economy of regions, development of interregional and international cooperation, stimulation of self-organizational processes, etc. These measures have to become a component of the strategy of management of social and economic and innovation development of regions.

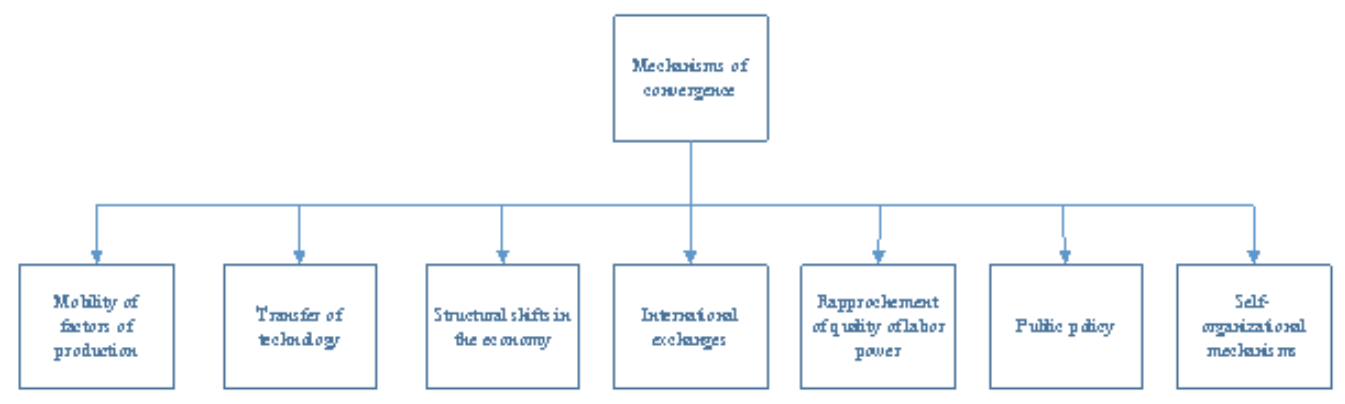

Figure 2. Mechanisms of convergence of social and economic systems

The factors and the speed analysis of convergence which is carried out by a number of the Russian authors (Dyatlov, 2000), showed that the main premises, engines of convergence of regions in modern conditions are transport and construction. They promote most mobility of major factors of production. Influence on processes of convergence of the agricultural industry and the industry is multidirectional. Therefore for decrease in level of an interregional inequality, including in the innovation sphere, it is reasonable to concentrate when developing strategy of development of regions 
efforts and resources on development of infrastructure, the agricultural industry and the industry in the respective regions. However experts note that globalization and integration processes happening in world economy cause dominance convergence processes, i.e. rapprochement of economies of the different countries and regions (Ryazantsev et al, 2014; Ryazantsev \& Bozhenko, 2014 \& Ryazantsev, 2007).

Some concepts of a hypothesis of convergence are mentioned in the modern economical literature. The greatest distribution was gained by two concepts - so-called beta and sigma convergence.

The concept of beta convergence ( $\beta$-convergence) defines convergence as the process of "making up" at which poor regions have higher rates of economic growth. Beta convergence - negative dependence of rates of economic growth on an initial level of development of the countries and regions.

The sigma convergence ( $\sigma$-convergence) is a decrease in time of the dispersion of levels of development of economic units. Hypotheses of $\beta$-convergence and $\sigma$ - convergences are interconnected but are not equivalent. The analysis of the interrelation of $\beta$-and $\sigma$ - convergences says that $\beta$-convergence is only a necessary condition $\sigma$ convergences. So, in Russia process of $\beta$ convergence is combined with $\sigma$ - convergence. The Rather significant initial gap between rich and poor regions is the reason of this combination. It is so great that higher growth rates in poor regions are not capable to reduce in the short-term period it in absolute expression.

According to a convergence hypothesis, if the region economy at the initial moment is further from the provision of stable equilibrium, rates of its growth will be higher, than at the economy, which is closer to balance. Therefore, in the long-term period differentiation can disappear. Most often the hypothesis of convergence is applied to studying of distinctions and dynamics in the GDP level (VRP) per capita.

Absolute (unconditional) convergence is a rapprochement of levels of development of the countries and regions in time.

Conditional convergence of the countries (regions) means convergence of the countries to own steady states that means lack of real rapprochement of levels of development of the countries and regions.

Distinguish convergence in growth rates, in income levels and the performance of factors, understanding as it smoothing of distinctions between the countries (regions) on the corresponding indicator.

According to the degree of certainty, distinguish between deterministic and stochastic convergence.

Some authors considers, that in the Russian economy of the loudspeaker of an interregional inequality on real VRP per capita corresponds to model of conditional convergence, and stationary conditions of long-term balance of economies of regions significantly differ between regions (lodchin, 2007).

In this work is offered the concept of convergent development of regions based on the application of the system and self-organizational approach. When developing the concept we recognize, that a phenomenon of convergence as the process of individual gradual integration, group (corporate) and public work can be opened via development mechanisms of social and economic systems. Its premises are structural and functional changes in these systems, which are in turn connected with the change of a ratio and role of the major institutes of public life - Institutes of self-organization and public administration.

The regional concept development is based on idea of harmonization of private, corporate and public concerns in the course of functioning of entrepreneurial, government and public institutions, and satisfaction of compelling needs of the main part of the population.

In countries with developed market relations of self-organization institutions plays a leading role, while the institutions of government regulation, in fact, appear complementary. The opposite pattern is observed in countries with economies in transition, where due to the need for government control and institutions regulation of the government must remain the leading and institutions of self-organization is expected to serve as complementary elements.

Immanent line of convergent national system consists in an equivalence of the dominating basic institutional orders. The process of convergence in such social and the economic system assumes the maximum complementarity of the specified orders. Thereby the characteristic sign of convergence of regional social and the economic system consists in an equilibration of institutes of self-organization and state regulation relatively each other. Therefore, the main benefit of a convergent model of development of social and economic system consists in the possibility of simultaneous use of potentials of the different institutional orders based on self-organization and public administration.

The concept "order" was introduced into scientific circulation by representatives of the German historical school, and then developed by Freiburg School. Development of this concept formed a basis for the creation of the theory of social market economy which idea of the organization became extremely popular in many countries. The German researcher, W. Eucken in work of "A basis of national economy" so, writes about an economic order: "Economic process always and everywhere proceeds within known forms, i.e. historically set economic order. Historically developed rules 
could be bad, but without any order it is impossible to manage" (Eucken, 1996).

The economic order is understood as a set of the formal and informal institutes providing functioning of separate farms. These institutional systems arise during historical development or are established by the state. If expand an economic concept of order to scales of a social and economic order, in this case it is necessary to enter into the analysis a number of additional components, such as the public institutes, political and legal and other aspects characterizing difficult interrelation of economy and society (Afonosova, 2009). However innovation management problems development are so diverse and complicated that the further researches in this area including systems analysis and theoretical synthesis of activity of governing bodies of federal and regional levels in the conditions of headed for institutional transformation and modernization of economy are necessary. Except the use of traditional methods of management of the innovation development, it is necessary to develop the new approaches and managerial technologies providing creation of institutional conditions and incentives for effective implementation of the innovation activity.

\section{Conclusion}

Use in practice region economy management model development on the basis of a combination of convergence and divergence can lead to emergence of synergy effect of interaction of subjects of economic activity in the form of strengthening of their innovation activity, more effective diffusion of knowledge and technologies (thanks to positive and negative feedback), increases in efficiency of communication processes. The regional economic system thus can purchase new qualities and become steadier and effective.

Results of the conducted research allow to draw a conclusion that concept implementation of convergent development of regions, turning on of the stabilization mechanisms connected with carrying out effective economic and innovation policy can significantly correct trajectories of economic dynamics of backward and depressive regions, thus having kept growth rates of successful regions. Therefore, the formulated concept, recommendations about its application and management model convergent development of the economy of the region can form a methodological basis when developing a strategy for management of the development of the Russian regions. It is especially actual in the modern conditions, that are characterized by the proceeding sanctions policy of the leading western countries for Russia, decrease in the world prices for energy carriers, rate fluctuations of national currency, need of overcoming of effects of financial and economic and geopolitical crisis.

The offered regions convergent development conceptgent development realized in effective innovation, economic and regional policy is capable not only to prevent increase of an interregional inequality, but also to provide increase of growth rates of economy due to expansion of interregional integration, more rational use of resource and innovation capacity of regions, increases in production factor mobility and quality of a human capital in backward and depressive regions. The dynamics interregional level inequality researches conducted by the author allowed to draw a conclusion that in the Russian Federation scales of interregional differentiation on an average per capita cash income of the population there is much less than scales of interregional differentiation on shower VRP. Convergence of an average per capita cash income in the conditions of VRP divergence is per capita caused by a factor of strengthening of extent of centralization of the tax and budget system and increase of efforts of the federal center in the field of redistribution policy. The business case of the region in case of convergent way of development choice will represent model of mixed economy with equal provision of institutes of a public (state) and private property, institutes of public regulation and market self-regulation. Such model can provide achievement of strategic objectives and desirable standards of public welfare.

\section{References}

Afonosova, M.A. (2009). Management of the innovation development of the region in the conditions of institutional transformation of the economy. Abstract of the doctor of economics. SPb.

Gavrilov, A.I. (2010). Regional economy and management: Studies. A benefit for higher education institutions. - M.: UNITY-DANA. pp. 239.

Solow, R.M. (1956). A Contribution to the Theory of Economic Growth: Quarterly Journal of Economics, No. 70.

Short economic dictionary (2005). Under the editorship of A.N. Azriliyan. 3rd prod. Moscow: Institute of the new economy.

Nefedova, T.G. (2008) Stratification of the cities and suburban space of Russia: Materials IV of the international scientific conference "The Innovation Development and Economic Growth". Moscow, Russian university of the friendship of the people.

Number and placement of the population (2010). Results of the All-Russian population census of 2010 Moscow, Federal State Statistics Service of the Russian Federation.

Iodchin, A.A. Econometric modeling of interregional convergence in Russia (The abstract of the master's thesis). Moscow, Moscow State 
University.

Karabulatova, I.S. (2001). Regional ethnolinguistics: A modern ethnolinguistic situation in the Tyumen region (based on toponym material). Tyumen. pp. 146.

Karabulatova I.S \& Polivara Z.V. (2013). Turkic and Slavs: bi-polylinguism in globalization and migrations (on an example of Tyumen region)//Middle-East Journal of Scientific Research 17 (6): 832-836.

Kovalenko, E.G. (2010). Regional economy, and management. Publishing house: St. Petersburg, St. Petersburg. pp. 288.

Svetunkov, C.G., Zagranovskaya A.V. \& Svetunkov, I.S. (2012). Complex-valued analysis and modeling of irregularity of social and economic development of regions of Russia. - SPb. pp. 129.

Dyatlov, S. A. (2000). Methodological convergence and analysis of macroparameters of network economy: Informational society, No. 5. St. Petersburg: Saint Petersburg State University of Economics and Finance.

Dosi J. \& Winter S.D. (2005). Interpretation of economic changes: evolution, structure and games//Magazine of the economic theory, No. 4.

Druker, P. (2012). Management. Challenges XXI century. M.: Mann, Ivanov, Ferber. pp. 240.

Walter, Eucken: (1965) Grundsätze der Wirtschaftspolitik. Rowohlt. Reinbek.

Eucken, W. (1996) Bases of the national economy. Moscow: Direktmedia of Publishing.

Bevzenko, L.D. (2003) Post-nonclassical science - possibility of social projections: Nonlinear dynamics and post-nonclassical science. Moscow: RAGS.

Dolyatovsky, VA., Kosakov A.I. \& Kokhanenko I.K. (2001) Methods of evolutionary and synergy economy in management. Rostov on Don: RGEU.

Ryazantsev, S.V., Pismennaya E.E., Karabulatova I.S. \& Charif Y.Akramov. (2014). The transformation of sexual and matrimonial behavior of Tajik labor migrants in Russia. In the: Asian Social Science. Vol 10, No. 20.

Rating of regions of GChP (2014). Development of public-private partnership in subjects of the Russian Federation. - M.: Center for the development of public-private partnership. pp. 20.

Podprugin, M.O. (2012). Sustainable development of the region: concept, main approaches, and factors//Russian entrepreneurship. 2012. - No. 24. pp. $214-221$.

The methodology of a rating of investment appeal of regions of Russia (2014). National Rating Agency.

Ryazantsev S.V. (2007). Labor migration in CIS and Baltic countries: tendencies, effects, regulation. M, the Formula it is right.

Ryazantsev S.V. \& Bozhenko V.V. (2014). New approaches to Managing labor migration under integration in Eurasec. In the Asian Social Science. Vol. 10, \#20, pp. 1-7. 
ISSN 2039-2117 (online) ISSN 2039-9340 (print)
Mediterranean Journal of Social Sciences MCSER Publishing, Rome-Italy
Vol 6 No 3 S4 May 2015 